\title{
Changes in fractional exhaled nitric oxide, exhaled carbon monoxide and pulmonary function during the acute attack, treatment and remission phases of pediatric asthma
}

\author{
Zhichao Xie, Mingrong Chai, Weiqiang Gu, Huizhen Yuan \\ Department of Pediatrics, Affiliated Dongguan People's Hospital, Southern Medical University (Dongguan People's Hospital), Dongguan, China \\ Contributions: (I) Conception and design: Z Xie, H Yuan; (II) Administrative support: All authors; (III) Provision of study materials or patients: All \\ authors; (IV) Collection and assembly of data: Z Xie, H Yuan; (V) Data analysis and interpretation: All authors; (VI) Manuscript writing: All authors; \\ (VII) Final approval of manuscript: All authors. \\ Correspondence to: Huizhen Yuan. Department of Pediatrics, Affiliated Dongguan People's Hospital, Southern Medical University (Dongguan People's \\ Hospital), Wandao Road, Xinguyong Community, Wanjiang District, Dongguan 523059, China. Email: 2485675418@qq.com.
}

\begin{abstract}
Background: The current study aimed to explore the value of fractional exhaled nitric oxide (FeNO), exhaled carbon monoxide (eCO), and pulmonary function in the management of asthmatic children.

Methods: One hundred children diagnosed with asthma were selected as research subjects. Patients were divided into a 3-5-year-old group and a group with children 6 years and older. They were also grouped depending on whether they had asthma alone (A0 group) or whether their asthma was complicated with allergic rhinitis (A+AR group). The FeNO, eCO levels, and pulmonary function in the acute attack period were analyzed 1 month after treatment and clinical remission period.

Results: Asthmatic children demonstrated greater pulmonary dysfunction and significantly higher FeNO and eCO during the acute attack phase compared to both one month after treatment and clinical remission. The remission phase was characterized by decreased levels of FeNO and eCO and improvement of pulmonary function. The eCO levels in children aged 3-5 years old, and both FeNO and eCO levels in children 6 years and older were statistically lower during remission regardless of whether the patients had asthma alone or asthma complicated with rhinitis. However, $10 \%$ of the 100 children in the clinical remission period still demonstrated mid to high levels of FeNO. The critical value of FeNO levels during the acute period in children 6 years and older with asthma and rhinitis was $34.5 \mathrm{ppb}$ (AUROC 0.814, 95\% CI: $0.684-0.944$ ) with a sensitivity of $69.2 \%$ and specificity of $93.7 \%$.
\end{abstract}

Conclusions: Dynamic monitoring of FeNO and eCO is an effective indicator of airway inflammation and thus represents an important clinical tool in assessing the severity of asthma in children.

Keywords: Children; asthma; fractional exhaled nitric oxide; exhaled carbon monoxide; pulmonary function

Submitted Sep 22, 2020. Accepted for publication Dec 08, 2020.

doi: $10.21037 /$ tp-20-351

View this article at: http://dx.doi.org/10.21037/tp-20-351

\section{Introduction}

Bronchial asthma is a heterogeneous disease characterized by chronic airway inflammation and airway hyperresponsiveness. Unfortunately, the prevalence of bronchial asthma continues to increase every year. Due to individual differences in children's growth and development, pediatric asthma diagnosis mainly depends on clinical manifestations. As clinical symptoms are diverse, diagnosis in younger children can be relatively difficult. Their treatment times tend to be prolonged and compliance is poor. As a result, they are prone to recurrent attacks. Prolonged asthma episodes can lead to irreversible stenosis and remodeling of the airways, which can seriously affect the child's physical and mental well-being (1). Therefore, it is very important to evaluate 
and monitor how well asthma is controlled and managed in children. Non-invasive examination methods (airway inflammation index test, lung ventilation function test, allergen test, asthma clinical assessment tool) have been discussed and studied in recent years. Common clinical assessments such as the asthma control level classification, c-ACT scores and TRACK tests (2) are subjective. Also, pulmonary function tests are affected by age and the degree of adaptability. Since the essence of asthma is chronic airway inflammation, it is particularly important to seek objective airway inflammation indicators that can be used to evaluate the efficacy of treatments at controlling the disease and help determine a prognosis.

In recent years, non-invasive detection of fractional exhaled nitric oxide (FeNO) and exhaled carbon monoxide (eCO) has attracted much attention. Relevant studies (3) showed that FeNO is related to the degree of airway inflammation, but it is easily affected by allergic diseases. Therefore, the use of $\mathrm{FeNO}$ as an indicator in the diagnosis, treatment and evaluation of pediatric asthma is still controversial. Also, there are currently very few reports on the relationship between eCO levels and pediatric asthma. To this end, our current study used prospective research methods to analyze the changes of FeNO, eCO and pulmonary function in 100 asthmatic children at different clinical stages of the disease.

We present the following article in accordance with the STARD reporting checklist (available at http://dx.doi. org/10.21037/tp-20-351).

\section{Methods}

\section{Research subjects}

According to the diagnostic criteria of pediatric bronchial asthma in the Guideline for the Diagnosis and Optimal Management of Asthma in Children (2016 Edition) (4), 100 asthmatic children aged 3-14 years were selected from July 2018 to June 2019 in the Pediatric Asthma Specialist Outpatient Department of Dongguan People's Hospital. As respiratory physiological functions vary greatly with age, the subjects were divided into a 3-5-year-old group and a 6 -year-and older ( $\geq 6$ years old). Children were further grouped according to whether they had asthma alone (A0 group) or asthma with allergic rhinitis (5) (A+AR group). According to the Guideline for the Diagnosis and Optimal Management of Asthma in Children (2016 Edition), stepwise and standardized individual treatment was administered. Pulmonary function, $\mathrm{FeNO}$ and eCO levels were monitored at three different stages of the clinical disease, the acute attack period, 1 month after treatment and the clinical remission period. The acute attack period refers to sudden onset of wheezing, cough, shortness of breath, chest tightness, or sharp aggravation of the original symptoms. The clinical remission phase refers to the disappearance of symptoms and pulmonary function recovery to levels before the acute attack and maintenance of this function for more than three months.

Patients with congenital respiratory diseases including bronchial stenosis and bronchial malformation were excluded. Patients exhibiting poor compliance and cooperation with repeated pulmonary function tests or FeNO and eCO tests were excluded. Patients who have consumed food or drugs that can affect the levels of FeNO and $\mathrm{eCO}$ within the specified monitoring time were also excluded. Signed informed consent was obtained from guardians of all patients. The study was approved by medical ethics committee of Affiliated Dongguan People's Hospital (KYKT2018-040). All procedures performed in this study involving human participants were in accordance with the Declaration of Helsinki (as revised in 2013). Because of the retrospective nature of the research, the requirement for informed consent was waived.

\section{FeNO and eCO assays}

Both $\mathrm{FeNO}$ and eCO detection were performed using a nanocoulomb exhalation analyzer (Sunvou-P100 type), in which FeNO detection mode or eCO detection mode can be selected. Children are growing and developing. Due to the different anatomical, physiological, immunological, pathological and other characteristics of the respiratory system in children with asthma at different ages, as well as the different degree of coordination, FeNO and ECO detection methods are inconsistent with those of adults. The levels of FeNO and eCO were measured in part per billion (ppb) and part per million (ppm), respectively. Before administering the $\mathrm{FeNO}$ and eCO tests, the procedure was explained to the children and they were also shown a video. Children aged 3-5 years were tested offline. An air storage bag that did not contain test gases was used. Children were required to inhale through a mouthpiece attached to the air storage bag. They were not allowed to hold their breath. A slow exhalation was performed under a certain exhalation resistance. Exhaled gases collected in the storage bag were analyzed. We should strictly grasp the diagnostic criteria 
of childhood asthma. To educate the children and their parents about the basic prevention and treatment of asthma, and mobilize their subjective initiative in the prevention and treatment of asthma, so as to improve the medical compliance of treatment and further improve the detection accuracy of children aged 3-5 years. Children 6 years and older were tested online. Children inhaled to their total lung volume as much as possible through the mouthpiece which contained a disposable bacterial filter and a test gas filter. Then they exhaled at a steady speed through the filter at a flow rate of $50 \mathrm{~mL} / \mathrm{s}$. The analyzer automatically completed the measurement, analysis and calculation.

\section{Pulmonary function}

German Yegge lung function instrument was used. Children aged 3-5 years were tested for pulmonary function by impulse oscillometry (IOS) following Series Guidelines for Pediatric Pulmonary Function (Part III): Impulse Oscillometry (6). Children were required to stand or sit in a quiet state. The mouthpiece was held in place with the lips tightly wrapped around it and the nose was clamped. The operator gently pressed both cheeks with both hands, and the child breathed evenly and calmly. Data was collected after the baseline was stable, and the sampling time was 60-90 s. The best waveforms (no less than $30 \mathrm{~s}$ ) were taken for data analysis and the results saved Total respiratory resistance (R5) and central respiratory resistance (R20) were recorded. Children 6 years and older were tested by conventional lung ventilation method following the Series Guidelines for Pediatric Pulmonary Function (Part II): Lung Volume and Spirometry (7). In a quiet state, the tested children's oral lips were tightly wrapped around a disposable mouthpiece connected with a sensor, and a nose clip was clamped. Under the pulmonary function instrument's flow volume curve measurement module, the children were guided to breathe calmly. After at least five stable tidal breathing waveforms were displayed, the subjects were allowed to inhale to their full lung capacity at maximum force and maximum speed until residual lung volume is reached. They then inhaled again to full lung capacity. During this procedure, the instrument automatically calculated and obtained the measurement parameters. The test was repeated at least three times and the best result selected. The percentage of forced expiratory volume of one second to the predicted value (FEV1), the percentage of one second rate to the predicted value (FEV1/FVC\%), the percentage of maximum middle expiratory flow to the predicted value (MMEF\%), and the percentage of $75 \%$ forced expiratory flow to the predicted value (FEF75\%) were recorded.

\section{Statistical analyses}

Data were analyzed by SPSS 25.0 software and expressed as mean \pm standard deviation $(\bar{x} \pm s)$. Chi-square test was used for sex ratio in A0 group and A+AR group, and t test of two independent samples was used for age comparison. One-way ANOVA was used to analyze the three groups' quantitative data, and Turkey method was used for pairwise comparison between the groups. Pearson correlation test was used to examine the correlation between FeNO, $\mathrm{eCO}$ and pulmonary function parameters. The diagnostic value of eCO and $\mathrm{FeNO}$ for asthma complicated with rhinitis was determined by receiver operating characteristic curve (ROC), and the area under the curve, sensitivity and specificity were calculated. Results were considered statistically significant when $\mathrm{P}<0.05$.

\section{Results}

\section{General conditions}

Among the 100 children with asthma, 64 were male and 36 were female, with an average age of $6.47 \pm 2.55$ years. There were 58 asthmatic children aged $3-5$ years, including 38 males and 20 females, with an average age of $4.86 \pm 1.01$. There were 42 asthmatic children 6 years and older, including 26 males and 16 females, with an average age of $8.83 \pm 2.21$ years. Depending on the presence of allergic rhinitis, patients were divided into the simple asthma group (A0 group) and the asthma combined with rhinitis group (A+AR group). There was no significant difference in age and gender between the two groups (Table 1, Table 2, $\mathrm{P}>0.05)$.

\section{$\mathrm{FeNO}, e \mathrm{CO}$ and pulmonary function of 58 asthmatic children aged 3-5 years in different clinical stages of asthma}

The FeNO, eCO and R20 values of asthmatic children aged $3-5$ years were significantly different in the acute attack period, one month after treatment and clinical remission period $(\mathrm{P}<0.05)$. The FeNO, eCO and $\mathrm{R} 20$ values in the acute attack period were significantly higher than those in clinical remission $\left(\mathrm{P}_{\mathrm{FeNO}}=0.001, \mathrm{P}_{\mathrm{eCO}}=0.000, \mathrm{P}_{\mathrm{R} 20}=0.000\right.$, 
Table 1 Comparison of general conditions of asthmatic children aged $3-5$ years

\begin{tabular}{lccc}
\hline Group & Cases & $\begin{array}{c}\text { Gender } \\
\text { (male/female) }\end{array}$ & $\begin{array}{c}\text { Age } \\
\text { (years) }\end{array}$ \\
\hline A0 & 23 & $15 / 8$ & $4.82 \pm 0.97$ \\
A+AR & 35 & $23 / 12$ & $4.87 \pm 1.05$ \\
Statistic quantity & & $0.002^{\mathrm{a}}$ & $0.183^{\mathrm{b}}$ \\
P & & 0.969 & 0.856 \\
\hline
\end{tabular}

A0 group represents children who only has asthma; $A+A R$ group represents children who combined with asthma and allergic rhinitis. a means statistical method using Chi-square tests; $b$ means statistical method using $T$ test.

Table 2 Comparison of general conditions of asthmatic children $\geq 6$ years old

\begin{tabular}{lccc}
\hline Group & Cases & $\begin{array}{c}\text { Gender } \\
\text { (male/female) }\end{array}$ & Age (years) \\
\hline A0 & 16 & $8 / 8$ & $8.44 \pm 1.89$ \\
A+AR & 26 & $18 / 8$ & $9.08 \pm 2.38$ \\
Statistic quantity & & $1.553^{\mathrm{a}}$ & $0.912^{\mathrm{b}}$ \\
P & & 0.214 & 0.367 \\
\hline
\end{tabular}

A0 group represents children who only has asthma; $A+A R$ group represents children who combined with asthma and allergic rhinitis. a means statistical method using Chi-square tests; $b$ means statistical method using $T$ test.

$\mathrm{P}<0.05)$. There was no significant difference between the above indexes in the acute attack period and one month after treatment $(\mathrm{P}>0.05)$. The $\mathrm{R} 5$ value had no significant difference among the three groups (Table 3, $\mathrm{P}>0.05$ ).

\section{FeNO and eCO values in astbmatic children aged 3-5 years in $A O$ group and $A+A R$ group at different clinical stages}

Among the 23 children aged 3-5 years in the A0 group, there was no statistically significant difference in FeNO value in the acute attack period, one month after treatment and clinical remission period $(\mathrm{P}>0.05)$. However, the difference in eCO value between the three different clinical periods was statistically significant $(\mathrm{P}<0.05)$, with eCO levels in the clinical remission period significantly lower than in the acute period (Table 4, $\mathrm{P}=0.011$ ).

Among the 35 children aged 3-5 years in the A+AR group, the differences in $\mathrm{FeNO}$ and $\mathrm{eCO}$ values in the acute period, one month after treatment and clinical remission period were statistically significant $(\mathrm{P}<0.05)$. The FeNO levels in the acute period and 1 month after treatment were significantly higher than that in the clinical remission period $\left(\mathrm{P}_{\mathrm{FeNO}}=0.000, \mathrm{P}_{\mathrm{FeNO}}=0.004 ; \mathrm{P}_{\mathrm{eCO}}=0.001, \mathrm{P}_{\mathrm{eCO}}=0.038\right)$. In both the $\mathrm{A} 0$ and $\mathrm{A}+\mathrm{AR}$ groups, there was no statistically significant difference between the acute period and 1 month after treatment period (Table $4, \mathrm{P}>0.05$ ).

\section{FeNO, eCO and pulmonary function of 42 asthmatic children 6 years and older in different clinical periods}

The FeNO value, eCO value and lung function related indexes (FEV1\%, FEV1/FVC\%, MMEF\%, FEF75\%) of 42 asthmatic children 6 years and older was statistically different between each of the three disease stages $(\mathrm{P}<0.05)$. The values of FeNO and eCO in the acute period were significantly higher than those in the clinical remission period (all $\mathrm{P}=0.000$ ), and were accompanied by significant improvement in the pulmonary indexes, FEV $1 \%$, FEV1/FVC \%, MMEF $\%$ and FEF75\% $\left(\mathrm{P}_{\mathrm{FEV} 1 \%}=0.010\right.$, $\left.\mathrm{P}_{\mathrm{FEV} 1 / \mathrm{FV} \%}=0.000, \mathrm{P}_{\mathrm{MMEF} \%}=0.028, \mathrm{P}_{\mathrm{FEF} 75 \%}=0.036\right)$. There was no statistically significant difference in $\mathrm{FeNO}$, eCO or lung function between the acute and one month after treatment (Table 5, P>0.05).

\section{$\mathrm{FeNO}$ and eCO values of asthmatic children 6 years and older in $A O$ and $A+A R$ groups in different clinical periods}

In asthmatic children 6 years and older of the A0 group and A+AR group, the differences of FeNO value and eCO value at three different clinical periods were statistically significant $(\mathrm{P}<0.05)$. In the $\mathrm{A} 0$ group, $\mathrm{FeNO}$ and eCO values in the acute period and one month after treatment were significantly higher than in the clinical remission period $\left(\mathrm{P}_{\mathrm{FeNO}}=0.025, \mathrm{P}_{\mathrm{FeNO}}=0.032 ; \mathrm{P}_{\mathrm{eCO}}=0.000, \mathrm{P}_{\mathrm{eCO}}=0.001\right)$. Similarly, in the A+AR group, $\mathrm{FeNO}$ and eCO values were significantly higher in the acute period and one month after treatment than the clinical remission period (all $\mathrm{P}=0.0001$ ). However, $\mathrm{FeNO}$ and eCO values were not significantly different between the acute period and 1 month after treatment period for both the $\mathrm{A} 0$ and $\mathrm{A}+\mathrm{AR}$ cohort (Table 6, $\mathrm{P}>0.05)$.

\section{Correlation between $\mathrm{FeNO}$ and eCO and lung function parameters}

In children with asthma, $\mathrm{FeNO}$ was positively correlated with eCO $(\mathrm{P}<0.05)$. Also, FeNO was negatively correlated 
Table 3 FeNO, eCO and pulmonary function of 58 asthmatic children aged 3-5 years in different clinical periods

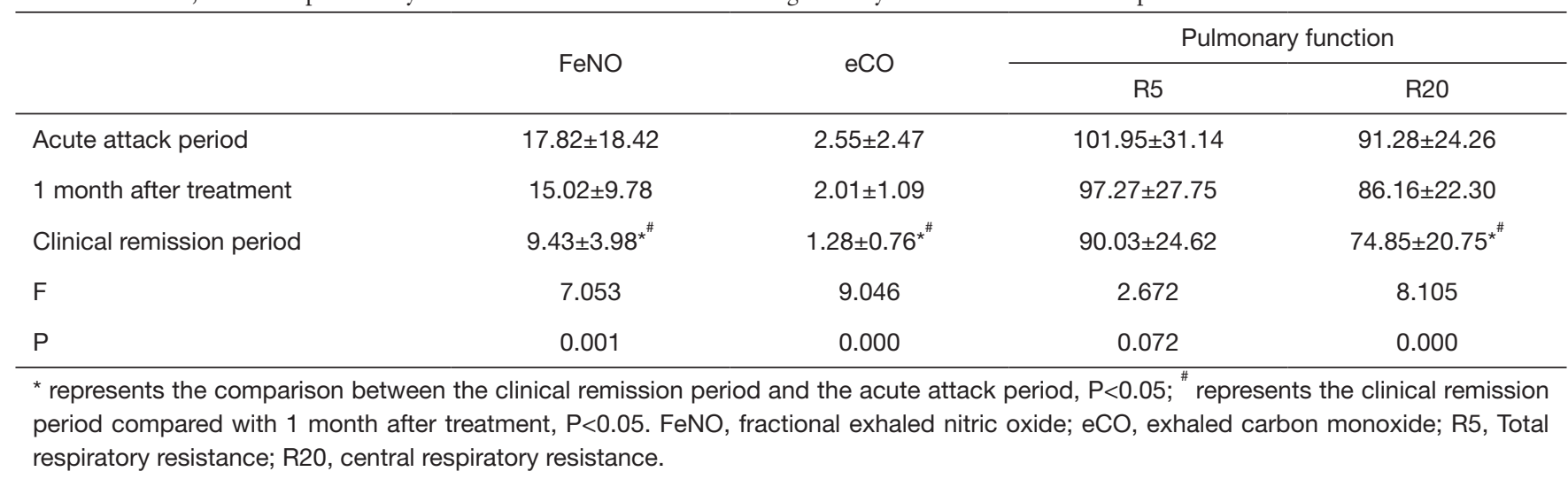

Table 4 FeNO and eCO values of asthmatic children aged 3-5 years in A0 group and A+AR group in different clinical periods

\begin{tabular}{|c|c|c|c|c|}
\hline & \multicolumn{2}{|c|}{ A0 group 23 cases } & \multicolumn{2}{|c|}{ A+AR group 35 cases } \\
\hline Acute period & $7.70 \pm 3.55$ & $2.65 \pm 2.67$ & $24.49 \pm 21.10$ & $2,49 \pm 2.37$ \\
\hline 1 month after treatment & $8.17 \pm 3.61$ & $1.95 \pm 1.13$ & $19.51 \pm 9.97$ & $2.04 \pm 1.08$ \\
\hline Clinical remission period & $8.82 \pm 3.85$ & $1.30 \pm 0.86^{\star}$ & $9.83 \pm 4.08^{\star^{\#}}$ & $1.26 \pm 0.69^{\star \#}$ \\
\hline$P$ & 0.58 & 0.04 & 0.000 & 0.005 \\
\hline
\end{tabular}

A0 group represents children who only has asthma; A+AR group represents children who combined with asthma and allergic rhinitis. * represents the comparison between the clinical remission period and the acute attack period, $\mathrm{P}<0.05 ;{ }^{*}$ represents the clinical remission period compared with 1 month after treatment, $\mathrm{P}<0.05$. FeNO, fractional exhaled nitric oxide; eCO, exhaled carbon monoxide.

Table $5 \mathrm{FeNO}$, eCO and pulmonary function of 42 asthmatic children $\geq 6$ years old in different clinical periods

\begin{tabular}{|c|c|c|c|c|c|c|}
\hline & FeNO & $\mathrm{eCO}$ & \multicolumn{4}{|c|}{ Pulmonary function } \\
\hline Acute period & $37.78 \pm 29.48$ & $4.12 \pm 2.06$ & $85.83 \pm 18.26$ & $94.81 \pm 13.06$ & $70.41 \pm 25.98$ & $67.73 \pm 30.14$ \\
\hline 1 month after treatment & $30.57 \pm 16.76$ & $3.26 \pm 1.15$ & $89.91 \pm 16.03$ & $98.51 \pm 8.89$ & $75.91 \pm 25.34$ & $73.67 \pm 25.62$ \\
\hline Clinical remission period & $14.30 \pm 7.82^{\star^{\#}}$ & $1.29 \pm 0.55^{\star^{\#}}$ & $96.56 \pm 15.33^{\star}$ & $104.30 \pm 10.52^{\star^{\#}}$ & $84.55 \pm 23.41^{*}$ & $82.52 \pm 25.11^{*}$ \\
\hline$P$ & 0.000 & 0.000 & 0.013 & 0.001 & 0.035 & 0.038 \\
\hline
\end{tabular}

* represents the comparison between the clinical remission period and the acute attack period, $\mathrm{P}<0.05$; ${ }^{*}$ represents the clinical remission period compared with 1 month after treatment, $\mathrm{P}<0.05$. FeNO, fractional exhaled nitric oxide; eCO, exhaled carbon monoxide; FEV1, The percentage of forced expiratory volume of one second to the predicted value; FEV1/FVC\%, the percentage of one second rate to the predicted value; MMEF\%, the percentage of maximum middle expiratory flow to the predicted value; FEF75\%, the percentage of $75 \%$ forced expiratory flow to the predicted value. 
Table $6 \mathrm{FeNO}$ and eCO values of asthmatic children $\geq 6$ years old in $\mathrm{A} 0$ and $\mathrm{A}+\mathrm{AR}$ groups in different clinical periods

\begin{tabular}{|c|c|c|c|c|}
\hline & \multicolumn{2}{|c|}{ A0 group (16 cases) } & \multicolumn{2}{|c|}{ A+AR group (26 cases) } \\
\hline Acute period & $19.69 \pm 9.62$ & $4.05 \pm 2.41$ & $48.92 \pm 32.11$ & $4.16 \pm 1.87$ \\
\hline 1 month after treatment & $19.38 \pm 12.28$ & $3.14 \pm 1.07$ & $37.46 \pm 15.51$ & $3.35 \pm 1.22$ \\
\hline Clinical remission period & $11.81 \pm 5.96^{\star \#}$ & $1.10 \pm 0.55^{\star^{\#}}$ & $15.85 \pm 8.53^{\star^{\#}}$ & $1.42 \pm 0.52^{*^{\#}}$ \\
\hline$P$ & 0.041 & 0.000 & 0.000 & 0.000 \\
\hline
\end{tabular}

* represents the comparison between the clinical remission period and the acute attack period, $\mathrm{P}<0.05 ;{ }^{\#}$ represents the clinical remission period compared with 1 month after treatment, $\mathrm{P}<0.05$. FeNO, fractional exhaled nitric oxide; eCO, exhaled carbon monoxide.

Table 7 Correlation between FeNO and lung function in 100 asthmatic children

\begin{tabular}{|c|c|c|c|c|c|c|c|}
\hline FeNO & $\mathrm{eCO}$ & \multicolumn{2}{|c|}{$3-5$ years old } & \multicolumn{4}{|c|}{$\geq 6$ years old } \\
\hline $\mathrm{R}$ & 0.507 & -0.073 & -0.048 & -0.155 & -0.181 & -0.103 & 0.029 \\
\hline$P$ & 0.000 & 0.336 & 0.526 & 0.082 & 0.042 & 0.251 & 0.746 \\
\hline
\end{tabular}

FeNO, fractional exhaled nitric oxide; eCO, exhaled carbon monoxide; R5, Total respiratory resistance; R20, central respiratory resistance; FEV1, The percentage of forced expiratory volume of one second to the predicted value; FEV1/FVC\%, the percentage of one second rate to the predicted value; MMEF\%, the percentage of maximum middle expiratory flow to the predicted value; FEF $75 \%$, the percentage of $75 \%$ forced expiratory flow to the predicted value.

with FEV1/FVC\% of lung function $(\mathrm{P}<0.05)$. Similarly, eCO was negatively correlated with $\mathrm{FEV} 1 \%$ and FEV1/ FVC\% of lung function $(\mathrm{P}<0.05)$. The FeNO and eCO values showed no significant correlation with R5, R20, MMEF\% and FEF75\% (Table 7, Table 8, $\mathrm{P}>0.05$ ).

\section{FeNO control level}

According to the offline detection method for children aged $3-5$ years, FeNO value less than age +13 ppb is a low level, between age $+13-35 \mathrm{ppb}$ is a medium level, and greater than $35 \mathrm{ppb}$ is a high level. For children 6 years and older, FeNO values less than $20 \mathrm{ppb}$ is low, ranging from 20 to $35 \mathrm{ppb}$ is medium, and greater than $35 \mathrm{ppb}$ is high (8). In this study, 100 asthmatic children reached clinical remission after treatment, and ten children $(10 \%)$ were still at moderate and high levels of FeNO. Two of 58 asthmatic children aged $3-5$ years $(3.4 \%)$ were at moderate FeNO levels in the clinical remission period. Of the 42 asthmatic children 6 years and older, seven $(16.6 \%)$ were at a moderate level of FeNO and 1 (2.4\%) was at a high level of FeNO (Table 9).

\section{Operating characteristic curve for FeNO}

The FeNO levels was significantly higher in the A+AR group compared to the A0 group for both the 3-5-year-old cohort and the 6 years and older cohort $\left(t_{3-5}\right.$ years $=11.342$, $\left.\mathrm{P}_{3-5 \text { years }}=0.001 ; \mathrm{t}_{\geq 6 \text { years }}=7.434, \mathrm{P}_{\geq 6 \text { years }}=0.009\right)(\mathrm{P}<0.05)$. However, the difference in eCO levels between the two groups was not statistically significant $\left(t_{3-5 \text { years }}=0.358\right.$, $\left.\mathrm{P}_{3-5 \text { years }}=0.552, \mathrm{t}_{\geq 6 \text { years }}=2.254, \mathrm{P}_{\geq 6 \text { years }}=0.141\right)(\mathrm{P}>0.05)$. Figure 1 shows the working characteristic curve of FeNO levels during the acute attack phase of asthma in children 6 years and older. The area under the curve (AUROC) for asthmatic children with rhinitis was 0.814 (95\% CI: 0.684-0.944) $(\mathrm{P}=0.000)$; the critical value of FeNO level was $34.5 \mathrm{ppb}$; the sensitivity was $69.2 \%$; and the specificity was $93.7 \%$. The area under the operating characteristic curve (AUROC) of eCO was 0.515 (95\% CI: 0.396-0.633) $(\mathrm{P}=0.807)$. Due to the influence of age, the FeNO levels in the 3-5-year-old group varied greatly in both the asthma only cohort and the asthma with rhinitis cohort. Therefore, a FeNO working characteristic curve could not be performed for this age group. 
Table 8 Correlation between eCO and lung function in 100 asthmatic children

\begin{tabular}{lcccccccc}
\hline \multirow{2}{*}{ eCO } & FeNO & \multicolumn{2}{c}{$3-5$ years old } & & \multicolumn{3}{c}{$\geq 6$ years old } \\
\cline { 3 - 4 } \cline { 6 - 8 } & & R5 & R20 & & FEV1\% & FEV1/FVC\% & MMEF\% & FEF75\% \\
\hline R & 0.507 & -0.072 & 0.030 & & -0.231 & -0.398 & -0.122 & -0.114 \\
$\mathrm{P}$ & 0.000 & 0.345 & 0.692 & & 0.009 & 0.000 & 0.174 & 0.205 \\
\hline
\end{tabular}

FeNO, fractional exhaled nitric oxide; eCO, exhaled carbon monoxide; R5, Total respiratory resistance; R20, central respiratory resistance; FEV1, the percentage of forced expiratory volume of one second to the predicted value; FEV1/FVC\%, the percentage of one second rate to the predicted value; MMEF\%, the percentage of maximum middle expiratory flow to the predicted value; FEF $75 \%$, the percentage of $75 \%$ forced expiratory flow to the predicted value.

Table 9 FeNO control levels in different clinical periods in 100 asthmatic children

\begin{tabular}{lccc}
\hline & $\begin{array}{c}\text { Low } \\
\text { level }\end{array}$ & $\begin{array}{c}\text { Medium } \\
\text { level }\end{array}$ & $\begin{array}{c}\text { High } \\
\text { level }\end{array}$ \\
\hline Acute period & 52 cases & 22 cases & 26 cases \\
1 month after treatment & 54 cases & 29 cases & 17 cases \\
Clinical remission period & 98 cases & 9 cases & 1 case \\
\hline
\end{tabular}

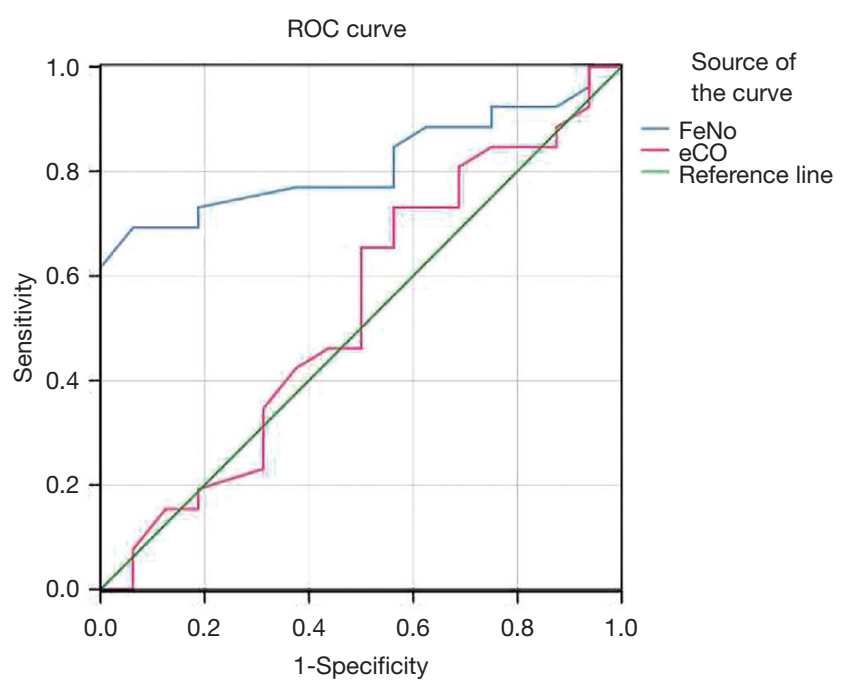

Figure 1 Area under FeNO curve in children aged $\geq 6$ years with asthma and rhinitis. FeNO, fractional exhaled nitric oxide; eCO, exhaled carbon monoxide; ROC, receiver operating characteristic curve.

\section{Discussion}

In this study, pulmonary function as well as $\mathrm{FeNO}$ and eCO levels in 100 asthmatic children was assessed during different clinical phases of the disease. It was found that the pulmonary function abnormalities in the acute attack period of asthmatic children were accompanied by significant increases in FeNO and eCO levels. After step-down and standardized treatment, the pulmonary function improvement in the clinical remission period was accompanied by significant decreases in $\mathrm{FeNO}$ and eCO levels $(\mathrm{P}<0.05)$. This is consistent with other scholars' research $(9,10)$ and supports the use of FeNO and eCO levels as a guide in the management of asthma treatment in children.

When airway inflammation occurs, airway epithelial cells overexpress inducible nitric oxide synthase (iNOS) under the stimulation of inflammatory cells, resulting in an abnormal increase of nitric oxide (NO) in the airway. There is good correlation between FeNO and eosinophilic inflammatory indexes such as induced sputum eosinophil count, peripheral blood eosinophil and total IgE.As such, FeNO is considered a marker of airway eosinophilic inflammation, and its level is susceptible to its own combined allergic diseases (11). Related studies have also shown that allergic rhinitis can also induce elevated FeNO level (12).

In the current longitudinal study, children 6 years and older who had asthma and allergic rhinitis demonstrated a significant increase in FeNO levels during the acute period. Following 1-month treatment, FeNO levels were significantly decreased along with remission of asthma symptoms and pulmonary function $(\mathrm{P}<0.05)$. Therefore, it is believed that FeNO, as a biomarker of airway inflammation, can be used as an index to evaluate asthma management's efficacy.

Xepapadaki and colleagues (13) conducted a 2-year follow-up of 167 preschool children, aged 4-6 years, with asthma, and found that the FeNO levels in asthmatic children with allergic constitution was significantly increased. This was consistent with our current study which demonstrated higher FeNO levels in asthmatic children 
with rhinitis. In the 3-5-year-old group with combined asthma and rhinitis, the FeNO levels were significantly higher in the acute period than in the clinical remission period $(\mathrm{P}<0.05)$. Within this age group, the level of FeNO in children with asthma alone was lower compared to children with both asthma and rhinitis. This was the case for all three clinical phases. Interestingly, FeNO levels in children with asthma alone did not change significantly between the acute phase, one month after treatment and the remission phase $(\mathrm{P}>0.05)$. These results suggested that FeNO levels' effectiveness as a marker in the control and evaluation of asthma in young children without rhinitis requires further research.

The above is different from the results observed in children aged 6 years and above with asthma alone. Children aged 3-5 years with asthma may exhibit noneosinophilic inflammation. Additionally, Xepapadak and other demonstrated that FeNO level can be elevated with time and age (13). The difference in results between the two age groups could also be attributed to different FeNO detection methods and difficulty controlling the degree of cooperation by younger children. It is interesting to note that in a meta-analysis on the relationship between FeNO and asthma treatment in children, it was believed that FeNO level had little effect in guiding asthma treatment (14). Considering that FeNO level is closely related to allergic status, it cannot effectively distinguish different types of allergic diseases (such as allergic asthma, allergic rhinitis, allergic dermatitis, etc.), and FeNO level of asthma and non-asthma children overlaps to a certain extent. On the other hand, not all asthmatic children respond to treatment with inhaled corticosteroids (ICS), which are significantly more effective for children with initial high FeNO level than for children with initial low FeNO level. However, children with initial low FeNO level need to be carefully evaluated for the effects of ICS, and active testing of other inflammatory markers is recommended, and combination therapy with other drugs should be considered if necessary. Therefore, the role of FeNO in the treatment assessment of asthma in children of different ages still needs to be further explored.

On the other hand, in this study, the FeNO level of children with rhinitis was significantly higher than that of children with asthma alone $(\mathrm{P}<0.05)$. The area under ROC curve of subjects with asthma and rhinitis diagnosed by $\mathrm{FeNO}$ was 0.814 ; the best cutoff point was $34.5 \mathrm{ppb}$; and the sensitivity and specificity for diagnosing asthma complicated with rhinitis were $69.2 \%$ and $93.7 \%(\mathrm{P}<0.05)$.
It is believed that FeNO levels higher than $34.5 \mathrm{ppb}$, can be suggestive that children with confirmed asthma may also suffer from allergic rhinitis, and it is recommended that allergic rhinitis be treated while controlling the acute attack of asthma. In this group of data, 10\% (10 cases) of the 100 asthmatic children who reached clinical remission after treatment were still exhibiting mid and high levels of FeNO. This indicated that although the clinical symptoms and signs of the remission period are controlled and the pulmonary function has gradually improved after treatment, there may indeed still be airway inflammation present. If the asthma treatment plan were to be adjusted at this time, care should be taken to find further and analyze the possible causes of the mid to high levels of FeNO. At present, studies have shown that persistently high levels of $\mathrm{FeNO}$ is a predictor of asthma recurrence (12), and FeNO can also be used as a detection index for sensitivity to glucocorticoid therapy (15). Therefore, in asthma treatment and management, FeNO can be used to indicate airway eosinophilic inflammation. Dynamic monitoring of its levels can reflect the active state of allergic diseases in the body, and may guide the management of treatment schemes for asthmatic children, thus reducing the relapse rate and the medical costs associated with asthma management. Brooks and colleagues (16) believed that clinical FeNO monitoring and evaluation can guide asthma management as an economic and effective method and reduce the expected annual expenditure (about USD 2228) on each patient. At present, FeNO level does not have the same cut-off value in the diagnosis of childhood asthma. We will expand the sample to improve the sensitivity in our further study.

Furthermore, endogenous carbon monoxide (CO) has been shown to regulate cytokine levels, vascular smooth muscle and hormone secretion in vivo, and has pathophysiological effects very similar to NO. Therefore, eCO also has clinical properties similar to FeNO. Relevant studies have shown that eCO can reflect not only airway inflammation, but also cell oxidative stress (17).

In our current study, eCO levels were positively correlated with FeNO levels $(\mathrm{P}<0.05)$. The eCO levels in asthmatic children is significantly higher during the acute period than in the clinical remission period $(\mathrm{P}<0.05)$. The investigations of many international researchers $(18,19)$ are consistent with this, and since eCO is easy to detect clinically, many advocate its use as a biomarker of asthma management. In the preschool children aged 3-5 years with simple asthma in this study, the eCO levels in the acute period were significantly higher than those in the 
clinical remission period $(\mathrm{P}<0.05)$. Moreover, there was no statistical significance in eCO levels between the simple asthma group and the group with asthma and rhinitis. This is the case for both the 3-5-year-old group and the 6 years and older group. This observation is inconsistent with the results examining FeNO levels in asthmatic children aged $3-5$ years and suggests that eCO may be a more sensitive indicator in assessing asthma management efficacy in children aged 3-5 years. Additionally, eCO appears to be less affected by other allergic diseases compared to FeNO.

Both $\mathrm{FeNO}$ and eCO are important means to evaluate airway inflammation, while pulmonary function is an important means to evaluate airway function in asthmatic children. The former are microscopic inflammation indexes, and the latter is a macroscopic ventilation index. The relationship between the two has attracted much attention. This study further analyzed the correlation between FeNO and eCO levels with pulmonary function. The levels of $\mathrm{FeNO}$ and eCO did not demonstrate any significant correlation with R5 and R20 in asthmatic children aged $3-5$ years.

In contrast to our current study, some scholars in China have demonstrated that $\mathrm{FeNO}$ combined with small airway function and pulmonary function parameters can accurately evaluate the severity of asthma in preschool children (20). Considering the small sample size and the normal measurement of pulse oscillation pulmonary function for mild obstructive diseases, the relationship between FeNO and eCO levels and airway obstruction in asthmatic children aged 3-5 years requires further research. Since bronchial provocation test can induce acute attacks of asthma, even severe cases (such as sitting breathing, panic, sweating, gray face, etc.), this study did not conduct bronchial dilation test and bronchial provocation test for asthmatic children to further determine the severity and clinical efficacy of the disease.

In the 6 years and older group in the current study, FeNO had a negative correlation with FEV1/FVC\% (but the correlation was weak, $\mathrm{P}=0.042$ ), and eCO had a significant negative correlation with FEV1 and FEV1/ FVC\% $(\mathrm{P}<0.05)$. However, FeNO is negatively correlated with FEV1\%, MMEF\% and FEF75\%, while eCO is negatively correlated with MMEF\% and FEF75\%, although there was no statistical significance $(\mathrm{P}>0.05)$. Other investigators (21) have observed similar results and believe that FeNO combined with pulmonary function parameters can improve cough variant asthma diagnosis sensitivity and specificity. Fielding and colleagues (22) followed up 1,112 asthmatic children and found that repeated monitoring of pulmonary function $\mathrm{FEV} 1 \%$ in children with remission of clinical symptoms can help assess the prognosis of asthma FeNO monitoring had little predictive effect. At present, the research results on the correlation between FeNO levels, eCO levels and pulmonary function at home and abroad are different, and the research results of this group of data suggest that FeNO and eCO can be used as auxiliary reference indicators to reflect airway stenosis and airway hyperresponsiveness of asthma in children 6 years and older. Since different pulmonary function parameters reflect the high degree of airway reactivity and different processes of airway remodeling in asthmatic children, it can be seen that FeNO, eCO and pulmonary function cannot replace each other, and the comprehensive management and evaluation of airway in asthmatic children can be more comprehensive only when combined.

In conclusion, this study believes that FeNO and eCO can be used as airway inflammation indicators to evaluate asthma management efficacy and can objectively evaluate the degree of inflammation and therapeutic response. When using FeNO determination to assist the diagnosis and management of asthma in children, if FeNO levels are normal, consideration should be given to whether asthma is caused by non-eosinophilic inflammation. If levels of FeNO are elevated, consideration should be given to the presence of allergic factors, and allergic diseases should be treated in conjunction with the management of asthma. However, eCO is less affected by allergic rhinitis. For asthmatic children, 6 years and older, FeNO and eCO levels can be used as auxiliary reference indicators to evaluate airway stenosis and airway hyperresponsiveness. In comparison, their assessment of the degree of airway obstruction in children aged 3-5 years will require further study. The combination of FeNO, eCO and pulmonary function tests and the formulation of individualized treatment plans are conducive to improving asthma control and management and reducing the incidence and exacerbation of asthma.

\section{Acknowledgments}

Funding: This research was funded and supported by The Key Projects of Dongguan City Social Science and Technology Development Plan (2018507150011654).

\section{Footnote}

Reporting Checklist: The authors have completed the STARD 
reporting checklist. Available at http://dx.doi.org/10.21037/ tp-20-351

Data Sharing Statement: Available at http://dx.doi. org/10.21037/tp-20-351

Conflicts of Interest: All authors have completed the ICMJE uniform disclosure form (available at http://dx.doi. org/10.21037/tp-20-351). The authors have no conflicts of interest to declare.

Ethical Statement: The authors are accountable for all aspects of the work in ensuring that questions related to the accuracy or integrity of any part of the work are appropriately investigated and resolved. Signed informed consent was obtained from guardians of all patients. All procedures performed in this study involving human participants were in accordance with the Declaration of Helsinki (as revised in 2013). All patients in the study signed informed consent. The study was approved by medical ethics committee of Affiliated Dongguan People's Hospital (KYKT2018-040). Because of the retrospective nature of the research, the requirement for informed consent was waived.

Open Access Statement: This is an Open Access article distributed in accordance with the Creative Commons Attribution-NonCommercial-NoDerivs 4.0 International License (CC BY-NC-ND 4.0), which permits the noncommercial replication and distribution of the article with the strict proviso that no changes or edits are made and the original work is properly cited (including links to both the formal publication through the relevant DOI and the license). See: https://creativecommons.org/licenses/by-nc-nd/4.0/.

\section{References}

1. Wong GW, Kwon N, Hong JG, et al. Pediatric asthma control in Asia: phase 2 of the Asthma Insights and Reality in Asia-Pacific (AIRIAP 2) survey. Allergy 2013;68:524-30.

2. Papadopoulos NG, Arakawa H, Carlsen KH, et al. International consensus on (ICON) pediatric asthma. Allergy 2012;67:976-97.

3. Dweik RA, Boggs PB, Erzurum SC, et al. An official ATS clinical practice guideline: interpretation of exhaled nitric oxide levels (FENO) for clinical applications. Am J Respir Crit Care Med 2011;184:602-15.

4. Respiratory Group, Pediatrics Branch of Chinese Medical
Association. Guidelines for the diagnosis and prevention of bronchial asthma in children (2016 edition). Chinese Journal of Pediatrics 2016;54:167-81.

5. List of members of the 11th Committee of the Otolaryngology Head and Neck Surgery Branch of the Chinese Medical Association. Chinese Journal of Otorhinolaryngology Head and Neck Surgery 2016;51:42.

6. Pulmonary Function Collaboration Group, R.G.P.B. Children's Lung Function Series Guide (III): Pulse Oscillation. Journal of Applied Clinical Pediatrics 2016;31:821-5.

7. Pulmonary Function Collaboration Group, R.G.P.B. Children's Lung Function Series Guide (II): Lung Volume and Ventilation Function. Chin J Appl Clin Pediatr 2016;31:744-50.

8. Visitsunthorn N, Prottasan P, Jirapongsananuruk O, et al. Is fractional exhaled nitric oxide $(\mathrm{FeNO})$ associated with asthma control in children? Asian Pac J Allergy Immunol 2014;32:218-25.

9. Petsky HL, Kew KM, Turner C, et al. Exhaled nitric oxide levels to guide treatment for adults with asthma. Cochrane Database Syst Rev 2016;9:CD011440.

10. Ryter SW, Choi AM. Carbon monoxide in exhaled breath testing and therapeutics. J Breath Res 2013;7:017111.

11. Ma'pol A, Hashim JH, Norbäck D, et al. FeNO level and allergy status among school children in Terengganu, Malaysia. J Asthma 2020;57:842-9.

12. Pijnenburg MW. The Role of FeNO in Predicting Asthma. Front Pediatr 2019;7:41.

13. Xepapadaki P, Korovessi P, Bachert C, et al. Evolution of Airway Inflammation in Preschoolers with Asthma-Results of a Two-Year Longitudinal Study. J Clin Med 2020;9:187.

14. $\mathrm{Lu} \mathrm{M}, \mathrm{Wu} \mathrm{B}, \mathrm{Che} \mathrm{D}$, et al. FeNO and asthma treatment in children: a systematic review and meta-analysis. Medicine (Baltimore) 2015;94:e347.

15. Yin SS, Liu H, Gao X. Elevated fractional exhaled nitric oxide $(\mathrm{FeNO})$ is a clinical indicator of uncontrolled asthma in children receiving inhaled corticosteroids. Int J Clin Pharmacol Ther 2017;55:66-77.

16. Brooks EA, Massanari M. Cost-Effectiveness Analysis of Monitoring Fractional Exhaled Nitric Oxide (FeNO) in the Management of Asthma. Manag Care 2018;27:42-8.

17. Shaoqing Y, Ruxin Z, Yingjian C, et al. A meta-analysis of the association of exhaled carbon monoxide on asthma and allergic rhinitis. Clin Rev Allergy Immunol 2011;41:67-75.

18. Jesenak M, Banovcin P, Havlicekova Z, et al. Factors influencing the levels of exhaled carbon monoxide in asthmatic children. J Asthma 2014;51:900-6. 
19. Pereira AA, Pollard SL, Locke R, et al. Association between exhaled carbon monoxide and asthma outcomes in Peruvian children. Respir Med 2018;145:212-6.

20. Zeng J, Chen Z, Hu Y, et al. Asthma control in preschool children with small airway function as measured by IOS and fractional exhaled nitric oxide. Respir Med 2018;145:8-13.

21. Zhu H, Zhang R, Hao C, et al. Fractional Exhaled Nitric Oxide (FeNO) Combined with Pulmonary Function

Cite this article as: Xie Z, Chai M, Gu W, Yuan H. Changes in fractional exhaled nitric oxide, exhaled carbon monoxide and pulmonary function during the acute attack, treatment and remission phases of pediatric asthma. Transl Pediatr 2020;9(6):784-794. doi: 10.21037/tp-20-351
Parameters Shows Increased Sensitivity and Specificity for the Diagnosis of Cough Variant Asthma in Children. Med Sci Monit 2019;25:3832-8.

22. Fielding S, Pijnenburg M, de Jongste JC, et al. Change in FEV1 and Feno Measurements as Predictors of Future Asthma Outcomes in Children. Chest 2019;155:331-41.

(English Language Editors: J. Teoh and J. Chapnick) 